Rev. Bras. Saúde Prod. Anim., Salvador, v.17, n.3, p.448-460 jul./set., $2016 \quad \underline{\text { http://www.rbspa.ufba.br }}$

\title{
Combinações de fontes de nitrogênio não proteico em suplementos para novilhos Nelore em pastejo
}

\author{
Combinations of non-protein nitrogen sources in supplements for Nellore steers \\ grazing
}

\author{
ÍTAVO, Luís Carlos Vinhas ${ }^{1 *}$; ÍTAVO, Camila Celeste Brandão Ferreira ${ }^{1}$; DIAS, \\ Alexandre Menezes ${ }^{1}$; FRANCO, Gumercindo Loriano ${ }^{1}$; PEREIRA, Luiz Carlos ${ }^{2}$; LEAL, \\ Eduardo Souza ${ }^{2}$; ARAÚJO, Hilda Silva ${ }^{1}$; SOUZA, Andréa Roberto Duarte Lopes ${ }^{1}$
}

\footnotetext{
${ }^{1}$ Universidade Federal de Mato Grosso do Sul, Faculdade de Medicina Veterinária e Zootecnia, Campo Grande, Mato Grosso do Sul, Brasil.

${ }^{2}$ Universidade Católica Dom Bosco, Campo Grande, Mato Grosso do Sul, Brasil.

*Endereço para correspondência: luis.itavo@ufms.br
}

\section{RESUMO}

Objetivou-se avaliar fontes de nitrogênio nãoproteico (NNP) combinadas para suplementação de novilhos Nelore na recria mantidos em pastagens diferidas. Após o deferimento de quatro piquetes de Brachiaria brizantha cv. MG4 por 60 dias (20 ha cada) 80 novilhos Nelore castrados, com peso corporal médio de $280,40 \pm 19,59 \mathrm{~kg}$, foram avaliados durante 120 dias. $\mathrm{O}$ manejo adotado foi pastejo rotacionado, com mudanças de piquetes a cada 15 dias. Foram avaliados quatro tratamentos com diferentes combinações de fontes de NNP: Ureia + Ureia extrusada + Ureia revestida; Ureia + Ureia revestida; Ureia + Ureia extrusada; Ureia extrusada. Em todos os tratamentos foram fornecidos suplemento proteico-energético-mineral ad libitum, com $30 \%$ de proteína bruta e $40 \%$ de nutrientes digestíveis totais.Quando avaliadas individualmente, as fontes de NNP apresentaram solubilidades distintas em água e solução tampão, sendo o menor valor observado para ureia revestida $(\mathrm{P}<0,05)$. Os animais dos tratamentos Ureia + Ureia extrusada + Ureia revestida e Ureia extrusa da apresentaram ganho médio diário superior $(0,4 \mathrm{~kg} / \mathrm{dia} ; \mathrm{P}<0,05)$ aos animais dos tratamentos Ureia + Ureia extrusada $(0,34 \mathrm{~kg} / \mathrm{dia})$. Os animais do tratamento Ureia extrusada apresentaram maior ganho de carcaça $(1,71$ @/animal) em relação aos demais $(\mathrm{P}<0,05)$. A margem líquida do tratamento Ureia extrusada ( $\mathrm{R} \$$ $158,20 /$ animal) foi superior em 10,8\%, 8,2\% e $35,8 \%$ aos tratamentos Ureia + Ureia extrusada + Ureia revestida, Ureia + Ureia revestida e Ureia +
Ureia extrusada, respectivamente. Recomenda-se a utilização de ureia extrusada como fonte de nitrogênio não proteico em suplementos para novilhos Nelore em pastagem diferida.

Palavras-chave: bovinos de corte, desempenho, solubilidade, ureia

\section{SUMMARY}

The objective of evaluating sources of non-protein nitrogen (NPN) combined for supplementation of Nelore steers in deferred pasture. After the deferral of four pickets of Brachiaria brizantha cv. MG4 (20 ha each) of 60 days, 80 Nellore steers, with average body weight $280.40 \pm 19.59 \mathrm{~kg}$, were evaluated for 120 days. The management adopted was rotational grazing, with pickets changes every 15 days. We evaluated four treatments with different combinations of NNP sources: Urea +Urea extruded + Urea coated; Urea + Urea coated; Urea + Urea extruded and Urea extruded. In all treatments were provided protein supplement-mineral energy ad libitum, with 30\% of crude protein and $40 \%$ of total digestibility nutrient. When evaluated individually, the NPN sources presented different solubility in water and buffer, and lowest value observed for coated urea $(\mathrm{P}<0.05)$.The animals of the treatments Urea + Ureaextruded + Urea coated and Urea extruded showed average daily gain $(0.4 \mathrm{~kg} / \mathrm{day} ; \mathrm{P}<0.05)$ of animals treatments Urea + Urea extrudedthe animals $(0.34 \mathrm{~kg} /$ day $)$.The animals of the Urea 
extruded treatment higher carcass gain (1.71 @/animal) compared to other $(\mathrm{P}<0.05)$.The net margin of the Urea extruded treatment (R \$ 158,20 /animal) was superior in $10.8 \%, 8.2 \%$ and $35.8 \%$ to treatments Urea + Urea + Urea coated, Urea + Ureaextruded and Urea + Ureacoated, respectively. It is recommended to use extruded urea as source of non-protein nitrogen (NPN) in supplements of Nellore steers in deferred pasture.

Keywords: beef cattle, performance, solubility, urea

\section{INTRODUÇÃO}

O diferimento das pastagens consiste na vedação do pasto no terço final do período chuvoso para o máximo acúmulo de forragem e aumento da disponibilidade para utilização dos animais durante a seca (SILVA et al. 2009). Porém, o valor nutritivo da forragem acumulada é baixo, especialmente teor de proteína (inferior a $7 \%$ ) e não atende as exigências nutricionais de bovinos de corte em recria.

Assim, para suprir a demanda de nutrientes do animal, torna-se necessário o fornecimento de suplementação alimentar balanceada no cocho, pois associada ao adequado manejo das pastagens, possibilita explorar o máximo potencial para desempenho e a produção de animais precoces para fase de terminação.

Existem diversos suplementos disponíveis para atendimento das exigências proteicas dos animais, como fontes de nitrogênio não proteico (NNP), consideradas de custo inferior às fontes de proteína verdadeira. As recomendações sobre a quantidade das fontes de NNP para inclusão na dieta de bovinos são bem estabelecidas na literatura (NRC, 2000), principalmente para utilização da ureia.

Porém, informações relacionadas ao uso de combinações de diferentes fontes de NNP disponíveis (ureia pecuária, ureia extrusada e ureia revestida) para fornecimento a animais na fase de recria em pastagens diferidas ainda são incipientes. $\mathrm{O}$ fornecimento de fontes de NNP combinadas pode trazer benefícios, pois o processamento sofrido pela ureia para produção da ureia extrusada e ureia revestida pode diminuir a solubilidade da fonte, reduzir os riscos de intoxicações e aumentar a eficiência de utilização do pasto pelo animal (RIBEIRO et al., 2011).

A obtenção de resultados para determinação da combinação ideal entre as fontes de NNP processadas ou para estabelecer recomendações de utilização individual em suplementos seria interessante sob aspectos produtivos $\mathrm{e}$ econômicos, pois o sincronismo da digestão dos carboidratos oriundos do material fibroso da pastagem diferida com uma liberação mais lenta do nitrogênio no rúmen pode melhorar a eficiência de síntese de proteína microbiana, aumentar a disponibilidade de proteína metabolizável para o animal e maximizar o ganho de peso.

Desta forma, formulou-se a hipótese que fontes combinadas de NNP com diferentes taxas de liberação de NNP no líquido ruminal, poderiam suprir de forma diferenciada os microrganismos ruminais afim de obter distintas velocidades de sincronização com as fontes de carbono disponíveis na dieta. Assim, objetivou-se avaliar diferentes combinações de fontes de nitrogênio não-proteico (NNP), para suplementação de novilhos Nelore na recria mantidos em pastagens diferidas.

\section{MATERIAL E MÉTODOS}

O experimento foi realizado na Fazenda Cabeceira da Lagoa, localizada em Bandeirantes-MS, entre os meses de Julho e Outubro de 2013. Foram utilizados 80 novilhos Nelore castrados, distribuídos em quatro tratamentos, com peso médio de $280,40 \pm 19,59 \mathrm{~kg}$. O projeto de pesquisa foi 
aprovado pela Comissão de Ética no Uso de animais (CEUA/UFMS) protocolo 366/2011.

Após 60 dias de diferimento da pastagem, antes da entrada dos animais nos piquetes, foram realizadas amostragens do capim para determinação da disponibilidade de forragem. Em cada piquete foram coletadas 10 amostras com quadrado de $1,0 \mathrm{~m}^{2}$, a cinco centímetros do solo para quantificação da disponibilidade de forragem por piquete e separação botânica de cada amostra em folha, colmo e material morto. A disponibilidade de material verde e material morto foi calculada por intermédio da extrapolação do resultado médio das amostragens em cada piquete para equivaler à área do hectare(CÓSER et al., 2002).

Em seguida, as amostras coletadas foram identificadas e secas em estufa de ventilação forçada a $65^{\circ} \mathrm{C}$ por 72 horas. Posteriormente foram pesadas e moídas para determinação dos teores de matéria seca, proteína bruta, fibra em detergente neutro e digestibilidade in vitro da matéria seca, segundo metodologias descritas por Detmann et al. (2012). Os procedimentos de coleta e análise do pasto posteriormente foram realizados a cada 30 dias, nos meses de Julho, Agosto, Setembro e Outubro de 2013.

Os animais foram distribuídos em quatro tratamentos com diferentes combinações de fontes de nitrogênio não proteicoa fim de se obter diferentes velocidades de solubilização do NNP: (1) rápida, média e lenta taxa de liberação ruminal do NNP (Ureia pecuária + Ureia extrusada + Ureia revestida); (2) rápida e lenta taxa de liberação ruminal do NNP (Ureia + Ureia revestida); (3) rápida e média taxa de liberação ruminal do NNP (Ureia + Ureia extrusada); (4) média taxa de liberação ruminal do NNP (Ureia extrusada).

Em todos os tratamentos foram fornecidos suplemento proteico-energético-mineral $a d$ libitum, com $30 \%$ de proteína bruta e $40 \%$ de nutrientes digestíveis totais (Tabela 1).

Tabela 1. Ingredientes $(\mathrm{g} / \mathrm{kg})$ dos tratamentos experimentais

\begin{tabular}{lcccc}
\hline \multicolumn{5}{c}{ Tratamentos } \\
\hline Ingredientes & $\begin{array}{c}\text { Ureia+Ureia extrusada } \\
\text { +Ureia revestida }\end{array}$ & $\begin{array}{c}\text { Ureia+Urei } \\
\text { a revestida }\end{array}$ & $\begin{array}{c}\text { Ureia+Ureia } \\
\text { extrusada }\end{array}$ & Ureia extrusada \\
\hline Núcleo mineral $^{1}$ & 559,45 & 567,76 & 557,13 & 542,85 \\
Ureia pecuaria $_{\text {Ureia extrusada }}^{23,81}$ & 35,71 & 35,72 & - \\
Ureia revestida & 33,34 & - & 50 & 100 \\
Farelo de algodão & 26,25 & 39,38 & - & - \\
\hline
\end{tabular}

${ }^{\mathrm{T}}$ Núcleo Mineral: Na: 44g/kg; P: 22g/kg; Ca: 40g/kg; S: 12g/kg; Mg: 3000mg/kg; Zn: 1500mg/kg; Cu: $500 \mathrm{mg} / \mathrm{kg}$; Co: $20 \mathrm{mg} / \mathrm{kg}$; I:30mg/kg; Se: $10 \mathrm{mg} / \mathrm{kg}$, Salinomicina $200 \mathrm{mg} / \mathrm{kg}$.

Todos os suplementos foram formulados para apresentar $30 \%$ de proteína bruta e $40 \%$ de nutrientes digestíveis totais, visando ganhos médios diários de $0,5 \mathrm{~kg} / \mathrm{dia}$ (NRC, 2000). Aproximadamente $33,3 \%$ do total de proteína bruta foi suprida com proteína verdadeira (Caroço de algodão: $23 \%$ de proteína bruta) e $66,7 \%$ do total com as combinações de fontes de nitrogênio não proteico (NNP): Ureia pecuária, Ureia extrusada (Amireia-200 ${ }^{\circledR}$, Pajoara Ind. e Comércio Ltda.) e Ureia revestida $\quad$ Optigen $^{\circledR}, \quad$ Alltech).Foram considerados os seguintes valores de equivalente proteico para as fontes de 
NNP: Ureia $280 \%$, Ureia extrusada: $200 \%$ e Ureia revestida: $254 \%$.

Além das análises bromatológicas do capim coletado nos piquetes, no início do experimento foram feitas análises laboratoriais das fontes de nitrogênio não proteico para avaliação da solubilidade. As análises foram realizadas no Laboratório de Biotecnologia aplicada à Nutrição Animal da Universidade Católica Dom Bosco, localizado em Campo Grande, MS. Para a determinação da solubilidade de cada fonte de nitrogênio não proteico, foi utilizado $0,5 \mathrm{~g}$ de fonte nitrogenada incubados em recipientes de vidro com capacidade para $250 \mathrm{~mL}$, aos quais foram adicionados $150 \mathrm{~mL}$ de água ou saliva artificial (solução tampão) mantido à $39^{\circ} \mathrm{C}$ em agitação constante.

A solubilidade foi calculada pela diferença entre o material incubado e o material residual após seis (6) horas consecutivas de incubação. A solução tampão (g/litro) foi composta por: $10,0 \mathrm{~g} \quad \mathrm{KH}_{2} \mathrm{P} 0_{4} ; \quad 0,5 \mathrm{~g}$ $\mathrm{MgSO}_{4} 7 \mathrm{H}_{2} \mathrm{O} ; 0,5 \mathrm{gNaCl} ; 0,1 \mathrm{~g} \mathrm{CaCl} 22 \mathrm{H}_{2} \mathrm{O}$; $0,5 \mathrm{~g}$ ureia, e a solução $\mathrm{B}(\mathrm{g} / 100 \mathrm{~mL}): 15,0 \mathrm{~g}$ $\mathrm{Na}_{2} \mathrm{CO}_{3} ; 1,0 \mathrm{~g} \mathrm{Na}_{2} \mathrm{~S} .9 \mathrm{H}_{2} \mathrm{O}$. As soluções foram misturadas na relação 1:5 para obter $\mathrm{pH}$ 6,8 em temperatura constante $\left(39^{\circ} \mathrm{C}\right)$.

Para determinação do nitrogênio amoniacal $\left(\mathrm{N}-\mathrm{NH}_{3}\right)$, foi utilizado $0,5 \mathrm{~g}$ de suplemento incubado em recipientes de vidro com capacidade para $250 \mathrm{~mL}$, aos quais foram adicionados $150 \mathrm{~mL}$ de água ou saliva artificial (solução tampão) mantido à $39^{\circ} \mathrm{C}$ em agitação constante. Para cada fonte, foram avaliadas quatro amostras em duplicata em diferentes tempos de coleta: $2,5,10,15,30,45,60,80,120,180,360$ minutos consecutivos. As concentrações de $\mathrm{N}-\mathrm{NH} 3$ foram determinadas mediante destilação com hidróxido de potássio $(\mathrm{KOH}) 2 \mathrm{~N}$.

Os animais foram distribuídos em quatro piquetes de 20 ha cada, previamente diferidos por 60 dias de pasto de capim Brachiaria brizantha cv. MG-4, providos de cochos e bebedouros. Foram avaliados
20 animais por tratamento. Os animais de cada tratamento receberam diariamente a suplementação ad libitum durante 120 dias e o consumo de suplemento foi estimado semanalmente, em função do total fornecido e das sobras no cocho $(20 \mathrm{~cm} /$ cabeça). O manejo adotado foi o pastejo contínuo, com lotação fixa (1 animal/hectare).

Para o cálculo do consumo de suplemento por tratamento foi considerado o valor diário por cabeça e o consumo de suplemento no período experimental (120 dias). As pesagens dos animais foram realizadas após 16 horas de jejum de sólidos ao início e a cada 30 dias até final do período experimental (120 dias). A cada 30 dias os animais foram redistribuídos em piquetes diferentes daquele em que estavam para evitar o efeito de piquete sobre o consumo de suplemento e desempenho dos animais.

O ganho médio diário foi obtido da relação entre o ganho total mensal e o número de dias avaliados ( $\mathrm{kg} / \mathrm{dia})$. Com as pesagens iniciais e finais do experimento foi calculado o ganho total do período $(\mathrm{kg})$ e estimado o ganho de carcaça (@/animal). Ao final do período experimental (120 dias), os custos $\mathrm{e}$ as margens líquidas foram calculados por animal e tratamentos, com cotações realizadas durante o mês de Agosto de 2014, em Campo Grande-MS.

Para os cálculos de receita foram consideradas as informações de ganho diário, transformados em arrobas (Ganho de Carcaça (@/animal)= Ganho total x $0,52 / 15$ ) e em seguida considerado o valor da arroba $($ Receita $(\mathrm{R} \$ /$ animal $)=$ Ganho de Carcaça (@/animal)x R\$ 122,00). Para o cálculo dos custos, foram considerados os valores investidos em cada suplemento $(\mathrm{R} \$ /$ saco e $\mathrm{R} \$ / \mathrm{kg})$ multiplicado pelo consumo total e diário por animal.

Para o cálculo da margem líquida, foram consideradas as diferenças entre receita e custos: Margem Líquida ( $\$$ \$animal) = Receita (R\$/animal) - Custo total com 
Rev. Bras. Saúde Prod. Anim., Salvador, v.17, n.3, p.448-460 jul./set., $2016 \quad \underline{\text { http://www.rbspa.ufba.br }}$ ISSN 15199940

suplemento ( $\mathrm{R} \$$ /animal);Margem Líquida $(\mathrm{R} \$ \mathrm{~kg}$ ganho $)=$ Margem Líquida (R\$/animal)/120dias/Ganho diário ( $\mathrm{kg} / \mathrm{dia})$; Margem Líquida $(\mathrm{R} \$ / @$ produzida $)=$ Margem Líquida (R\$/animal)/ Ganho de Carcaça (@/animal).

$\mathrm{O}$ delineamento experimental foi em inteiramente casualizado, com quatro tratamentos e 20 repetições por tratamento, totalizando 80 animais em quatro piquetes.

Para as avaliações da solubilidade in vitro e concentração de nitrogênio amoniacal das fontes de nitrogênio não proteico $o$ delineamento experimental foi inteiramente casualizado com 3 tratamentos (fontes de NNP).

$\mathrm{O}$ modelo estatístico utilizado foi $\mathrm{Yi}=\mu+$ $\mathrm{Si}+$ eij, onde: $\mathrm{Yi}=$ é a observação k, referente ao suplemento $i ; \mu=$ é a constante geral; $\mathrm{Si}=$ é o efeito do suplemento contendo diferentes combinações de fontes de NNP i; eijk = erro aleatório associado a cada observação Yi. Os dados foram avaliados por meio de análise de variância e as médias comparadas pelo teste Tukey, em 5\% de significância.

\section{RESULTADOS E DISCUSSÃO}

A disponibilidade média de matéria verde total ao início do experimento foi $8,7 \mathrm{t}$ MS/ha (Tabela2), com 69,5\% de digestibilidade in vitro da MS (DIVMS), $10,6 \%$ de proteína bruta e $63,9 \%$ de fibra em detergente neutro. No decorrer do experimento, a disponibilidade reduziu e a composição bromatológica do capim sofreu alterações devido ao consumo da forragem pelos animais.

Tabela 2. Material verde e material morto da pastagem de Brachiariabrizanthacv. MG4. coletadasnos meses de Julho (após 60 dias de diferimento), Agosto, Setembro e Outubro (120 dias de experimento)

\begin{tabular}{|c|c|c|c|c|}
\hline \multirow{2}{*}{ Meses } & Disponibilidade total (kg MS/ha) & PB\% & FDN\% & DIVMS\% \\
\hline & \multicolumn{4}{|c|}{ Material Verde } \\
\hline Julho & $8.754,9$ & 10,63 & 63,94 & 69,49 \\
\hline Agosto & $1.506,1$ & 9,15 & 65,70 & 52,45 \\
\hline Setembro & 934,2 & 6,25 & 65,96 & 54,25 \\
\hline \multirow[t]{2}{*}{ Outubro } & 897,0 & 6,41 & 66,29 & 55,03 \\
\hline & \multicolumn{4}{|c|}{ Material Morto } \\
\hline Julho & $4.315,4$ & 4,10 & 77,28 & 44,15 \\
\hline Agosto & $6.377,7$ & 3,85 & 76,01 & 32,87 \\
\hline Setembro & $2.280,2$ & 2,63 & 75,42 & 36,62 \\
\hline Outubro & $2.736,8$ & 2,92 & 78,00 & 39,20 \\
\hline
\end{tabular}

$\mathrm{PB}=$ proteína bruta; FDN = fibra em detergente neutro; DIVMS = digestibilidade in vitro da MS.

Ao final do período experimental é possível observar redução na quantidade de material morto, redução dos teores de proteína bruta e elevado teor de fibra. Consequentemente houve redução da digestibilidade in vitro da matéria seca, tanto no material verde $(55,03 \%)$ quanto no morto (39,20\%). Observa-se, ainda, acréscimo na proporção de material morto em relação ao verde, resultando em qualidade inferior da forragem disponível.

Estes resultados eram esperados, pois durante o diferimento ocorre crescimento excessivo da forrageira e acúmulo de material verde fibroso, que associado ao envelhecimento natural do pastoe a seleção 
Rev. Bras. Saúde Prod. Anim., Salvador, v.17, n.3, p.448-460 jul./set., $2016 \quad \underline{\text { http://www.rbspa.ufba.br }}$

de plantas em rebrota pelos animais resulta diminuição do valor nutritivo da massa residual disponível (SCHIO et al., 2011).

As médias de solubilidade in vitro das fontes nitrogenadas incubadas em água e solução tampão a $39^{\circ} \mathrm{C}$ diferiram entre as fontes de nitrogênio não proteico (Tabela $3)$.

A solubilidade da ureia em água e solução tampão foi superior às médias das demais fontes $(\mathrm{P}<0,05)$. Este resultado era esperado, uma vez que a literatura(NRC, 2000; COSTA et al., 2011; RIBEIRO et al., 2011) relata alta solubilidade da ureia no rúmen, fato que justifica sua inclusão na dieta dos animais combinadas a fontes de liberação mais lenta para proporcionar sincronismo entre a degradação do material fibroso da pastagem e utilização do nitrogênio amoniacal para síntese de proteína microbiana.

Tabela 3. Solubilidade média de produtos nitrogenados, em água, em função do tempo de incubação in vitro à $39^{\circ} \mathrm{C}$

\begin{tabular}{lccc}
\hline Tempo (minutos) & Ureia & Ureia extrusada & Ureia revestida \\
\hline 2 & & Solubilidade em água & $27,33^{\mathrm{c}}$ \\
5 & $96,60^{\mathrm{a}}$ & $62,66^{\mathrm{b}}$ & $28,14^{\mathrm{c}}$ \\
10 & $95,98^{\mathrm{a}}$ & $67,21^{\mathrm{b}}$ & $30,24^{\mathrm{b}}$ \\
15 & $96,45^{\mathrm{a}}$ & $64,55^{\mathrm{b}}$ & $34,12^{\mathrm{c}}$ \\
30 & $96,57^{\mathrm{a}}$ & $67,16^{\mathrm{b}}$ & $27,04^{\mathrm{b}}$ \\
45 & $97,48^{\mathrm{a}}$ & $65,00^{\mathrm{b}}$ & $42,58^{\mathrm{b}}$ \\
60 & $96,47^{\mathrm{a}}$ & $64,57^{\mathrm{b}}$ & $32,03^{\mathrm{c}}$ \\
80 & $96,42^{\mathrm{a}}$ & $63,42^{\mathrm{b}}$ & $45,85^{\mathrm{b}}$ \\
120 & $100,00^{\mathrm{a}}$ & $63,86^{\mathrm{b}}$ & $32,19^{\mathrm{c}}$ \\
180 & $89,34^{\mathrm{a}}$ & $67,82^{\mathrm{b}}$ & $45,73^{\mathrm{c}}$ \\
360 & $93,57^{\mathrm{a}}$ & $66,39^{\mathrm{b}}$ & $46,66^{\mathrm{c}}$ \\
\hline & $68,49^{\mathrm{a}}$ & $61,25^{\mathrm{b}}$ & $34,93^{\mathrm{c}}$ \\
2 & & Solubilidade em solução tampão & $41,14^{\mathrm{c}}$ \\
5 & $95,20^{\mathrm{a}}$ & $69,19^{\mathrm{b}}$ & $43,20^{\mathrm{c}}$ \\
10 & $64,62^{\mathrm{a}}$ & $62,95^{\mathrm{b}}$ & $46,65^{\mathrm{c}}$ \\
30 & $64,82^{\mathrm{a}}$ & $66,02^{\mathrm{b}}$ & $28,64^{\mathrm{b}}$ \\
45 & $94,75^{\mathrm{a}}$ & $69,30^{\mathrm{b}}$ & $22,24^{\mathrm{b}}$ \\
60 & $95,34^{\mathrm{a}}$ & $65,87^{\mathrm{b}}$ & $28,00^{\mathrm{c}}$ \\
80 & $91,97^{\mathrm{a}}$ & $62,69^{\mathrm{b}}$ & $29,47^{\mathrm{c}}$ \\
120 & $90,47^{\mathrm{a}}$ & $63,96^{\mathrm{b}}$ & $35,76^{\mathrm{c}}$ \\
180 & $90,70^{\mathrm{a}}$ & $67,70^{\mathrm{b}}$ & $36,53^{\mathrm{c}}$ \\
360 & $86,39^{\mathrm{a}}$ & $64,41^{\mathrm{b}}$ & $41,90^{\mathrm{c}}$ \\
\hline
\end{tabular}

Médias seguidas por letra minúscula na mesma linha diferem entre si pelo teste Tukey $(\mathrm{P}<0,05)$.

Quando a ureia é oferecida ao animal sem processamento é imediatamente atacada por uréases bacterianas e degradada, aumentando a produção de nitrogênio amoniacal, que se não for utilizado imediatamente para síntese de proteína microbiana pode acumular no rúmen e causar intoxicações ao animal.
Esta premissa pode ser confirmada pelas informações de concentração de nitrogênio amoniacal obtidas in vitro. Foi observada média superior de concentração de nitrogênio amoniacal da fonte ureia em relação às demais fontes $(\mathrm{P}<0,05)$ (Tabela 4). 
Rev. Bras. Saúde Prod. Anim., Salvador, v.17, n.3, p.448-460 jul./set., $2016 \quad \underline{\text { http://www.rbspa.ufba.br }}$ ISSN 15199940

A solubilidade e a concentração de nitrogênio amoniacal da ureia extrusada foi inferior ao valor observado para a ureia, no entanto superior em relação aos valores destas variáveis observados para ureia revestida $(\mathrm{P}<0,05)$. Tal fato indica que ao reduzir a solubilidade, a extrusão da ureia permite a liberação mais lenta do nitrogênio no ambiente ruminal quando comparada à ureia sem processamento.

Tabela 4. Concentração de N-amoniacal média de produtos nitrogenados, em água e em solução tampão, em função do tempo de incubação in vitro à $39^{\circ} \mathrm{C}$

\begin{tabular}{lccc}
\hline Tempo (minutos) & Ureia & Ureia extrusada & Ureia revestida \\
\hline & Concentração de Nitrogênio amoniacal $(\mathrm{mg} / 100 \mathrm{~mL})$ em água & \\
\hline 2 & $60,46^{\mathrm{a}}$ & $28,74^{\mathrm{b}}$ & $15,12^{\mathrm{c}}$ \\
5 & $42,62^{\mathrm{a}}$ & $30,25^{\mathrm{b}}$ & $18,15^{\mathrm{c}}$ \\
10 & $48,41^{\mathrm{a}}$ & $32,03^{\mathrm{b}}$ & $28,75^{\mathrm{c}}$ \\
15 & $60,52^{\mathrm{a}}$ & $35,06^{\mathrm{b}}$ & $27,21^{\mathrm{c}}$ \\
30 & $66,57^{\mathrm{a}}$ & $51,44^{\mathrm{b}}$ & $19,66^{\mathrm{c}}$ \\
45 & $51,44^{\mathrm{a}}$ & $39,33^{\mathrm{b}}$ & $24,19^{\mathrm{c}}$ \\
60 & $57,48^{\mathrm{a}}$ & $40,85^{\mathrm{b}}$ & $19,58^{\mathrm{c}}$ \\
80 & $60,48^{\mathrm{a}}$ & $33,28^{\mathrm{b}}$ & $21,15^{\mathrm{c}}$ \\
120 & $62,01^{\mathrm{a}}$ & $43,88^{\mathrm{b}}$ & $30,22^{\mathrm{c}}$ \\
180 & $54,46^{\mathrm{a}}$ & $51,44^{\mathrm{b}}$ & $24,17^{\mathrm{c}}$ \\
360 & $57,06^{\mathrm{a}}$ & $48,40^{\mathrm{b}}$ & $31,75^{\mathrm{c}}$ \\
\hline & Concentração de Nitrogênio amoniacal $(\mathrm{mg} / 100 \mathrm{~mL})$ & \\
\hline 2 & $66,55^{\mathrm{a}}$ & $45,40^{\mathrm{b}}$ & $16,64^{\mathrm{c}}$ \\
5 & $60,49^{\mathrm{a}}$ & $40,84^{\mathrm{b}}$ & $10,58^{\mathrm{c}}$ \\
10 & $65,04^{\mathrm{a}}$ & $37,83^{\mathrm{b}}$ & $18,16^{\mathrm{c}}$ \\
15 & $72,63^{\mathrm{a}}$ & $40,83^{\mathrm{b}}$ & $21,17^{\mathrm{c}}$ \\
30 & $72,62^{\mathrm{a}}$ & $33,26^{\mathrm{b}}$ & $22,68^{\mathrm{c}}$ \\
45 & $54,46^{\mathrm{a}}$ & $34,78^{\mathrm{b}}$ & $24,20^{\mathrm{c}}$ \\
60 & $45,36^{\mathrm{a}}$ & $37,82^{\mathrm{b}}$ & $28,73^{\mathrm{c}}$ \\
80 & $40,83^{\mathrm{a}}$ & $43,88^{\mathrm{b}}$ & $21,17^{\mathrm{c}}$ \\
120 & $62,03^{\mathrm{a}}$ & $30,26^{\mathrm{b}}$ & $37,80^{\mathrm{b}}$ \\
180 & $60,50^{\mathrm{a}}$ & $42,36^{\mathrm{b}}$ & $40,83^{\mathrm{b}}$ \\
360 & $77,13^{\mathrm{a}}$ & $41,11^{\mathrm{b}}$ & $40,85^{\mathrm{b}}$ \\
\hline
\end{tabular}

Médias seguidas por letra minúscula na mesma linha diferem entre si pelo teste Tukey $(\mathrm{P}<0,05)$.

Assim, esta fonte de nitrogênio não proteico apresenta potencial de utilização em suplementos de bovinos de corte para prevenir intoxicações, pois ao evitar o acúmulo de nitrogênio amoniacal no rúmen ea absorção excessiva pelas papilas ruminais, que sobrecarrega $o$ ciclo da ureia no fígado, diminui as perdas energéticas pelo animal.

A ureia revestida apresentou menor solubilidade e concentração de nitrogênio amoniacal quando incubada em ambas as soluções $(\mathrm{P}>0,05)$. Estes resultados corroboram com Ribeiro et al. (2011), que observaram menor solubilidade da ureia revestida em relação a ureia convencional ao avaliarem as fontes em suplementos para bovinos de corte alimentados com forragem de baixa qualidade.

Diferentemente da ureia extrusada, cujo principio de processamento é o aquecimento, a ureia revestida é obtida pelo encapsulamento da ureia com 
material resistente (LIZARAZO et al., 2014). Dessa forma, ao invés de estar parcialmente disponível para degradação pelas bactérias ureolíticas no rúmen, o revestimento da cápsula da ureia pode se tornar uma barreira física para o acesso dos microrganismos e retardar o processo de degradação a ponto de diminuir a solubilidade e a disponibilidade de nitrogênio para utilização pelos microrganismos ruminais.

Houve efeito de fonte de nitrogênio sobre o desempenho dos animais (Tabela 5).Os animais do tratamento Ureia+Ureia extrusada+Ureia revestida e Ureia extrusada apresentaram peso corporal final superior $(\mathrm{P}<0,05)$ aos animais dos tratamentos Ureia+Ureia revestida e Ureia+Ureia extrusada, que não diferiram entre si $(\mathrm{P}>0,05)$. Quanto ao consumo de suplemento (expressos em $\mathrm{kg} / \mathrm{dia}$ ou total/animal), foram observadas médias superiores de consumo nos tratamentos Ureia+Ureia extrusada+Ureia revestida e
Ureia+Ureia revestida em relação aos demais tratamentos $(\mathrm{P}<0,05)$. A média de consumo do tratamento Ureia+Ureia extrusada foi inferior a média do tratamento Ureia extrusada $(\mathrm{P}<0,05)$. Embora os animais do tratamento ureia extrusada tenham apresentado menor consumo em relação aos animais suplementados com as três fontes de nitrogênio ou com a Ureia+Ureia revestida, foi observado ganho de peso superior $(\mathrm{P}<0,05)$. Isto indica que ureia extrusada, por ser uma fonte de liberação de nitrogênio de média solubilidade (Tabela 2 ), pode ter sido utilizada com maior eficiência pelos microrganismos ruminais e possibilitou a sincronia adequada entre a digestão do carboidrato fibroso da forragem e a liberação do nitrogênio da fonte para síntese de proteína microbiana. A presença da ureia extrusada no tratamento com as três fontes combinadas também proporcionou ganho de peso total superior aos demais $(\mathrm{P}<0,05)$.

Tabela 5. Peso corporal inicial (PCI), peso corporal final (PCF), consumo de suplemento (CS), consumo total de suplemento (CTS), ganho médio diário (GMD), ganho total (GT) e ganho de carcaça (GC) de novilhos Nelore suplementados em pastagem diferida de Brachiariabrizantha cv. MG4

\begin{tabular}{lcccc}
\hline \multirow{2}{*}{ Variáveis } & \multicolumn{4}{c}{ Tratamentos $^{\#}$} \\
\cline { 2 - 5 } & $\begin{array}{c}\text { Ureia+Ureia extrusada } \\
+ \text { Ureia revestida }\end{array}$ & $\begin{array}{c}\text { Ureia+Ureia } \\
\text { revestida }\end{array}$ & $\begin{array}{c}\text { Ureia+Ureia } \\
\text { extrusada }\end{array}$ & $\begin{array}{c}\text { Ureia } \\
\text { extrusada }\end{array}$ \\
\hline PCI (kg) & $280,55^{\mathrm{a}}$ & $280,45^{\mathrm{a}}$ & $280,20^{\mathrm{a}}$ & $280,35^{\mathrm{a}}$ \\
PCF (kg) & $327,70^{\mathrm{a}}$ & $321,40^{\mathrm{b}}$ & $324,31^{\mathrm{b}}$ & $329,6^{\mathrm{a}}$ \\
CS (kg/dia) & $0,41^{\mathrm{a}}$ & $0,41^{\mathrm{a}}$ & $0,28^{\mathrm{c}}$ & $0,35^{\mathrm{b}}$ \\
CTS(kg/animal) & $49,20^{\mathrm{a}}$ & $49,33^{\mathrm{a}}$ & $33,65^{\mathrm{c}}$ & $42,45^{\mathrm{b}}$ \\
GMD(kg/dia) & $0,39^{\mathrm{ab}}$ & $0,34^{\mathrm{c}}$ & $0,37^{\mathrm{b}}$ & $0,41^{\mathrm{a}}$ \\
GMD julho & $1,04^{\mathrm{a}}$ & $1,08^{\mathrm{a}}$ & $0,83^{\mathrm{b}}$ & $0,89^{\mathrm{b}}$ \\
GMD agosto & $0,59^{\mathrm{c}}$ & $0,72^{\mathrm{b}}$ & $0,69^{\mathrm{b}}$ & $0,78^{\mathrm{a}}$ \\
GMD setembro & $0,27^{\mathrm{a}}$ & $-0,13^{\mathrm{d}}$ & $-0,02^{\mathrm{c}}$ & $0,04^{\mathrm{b}}$ \\
GMD outubro & $-0,29^{\mathrm{b}}$ & $-0,28^{\mathrm{b}}$ & $-0,02^{\mathrm{a}}$ & $-0,06^{\mathrm{a}}$ \\
GT (kg/animal) & $47,15^{\mathrm{a}}$ & $40,95^{\mathrm{b}}$ & $44,11^{\mathrm{b}}$ & $49,25^{\mathrm{a}}$ \\
GC(@/animal) & $1,63^{\mathrm{b}}$ & $1,42^{\mathrm{d}}$ & $1,53^{\mathrm{c}}$ & $1,71^{\mathrm{a}}$ \\
\hline
\end{tabular}

Médias seguidas por letra minúscula na mesma linha diferem entre si pelo teste Tukey $(\mathrm{P}<0,05)$. 
Por outro lado, a presença de ureia revestida no suplemento em substituição parcial à ureia proporcionou menor ganho de peso $(\mathrm{P}<0,05)$, mesmo com valor superior de consumo $(\mathrm{kg} / \mathrm{dia} \mathrm{e}$ total/animal). Estes resultados indicam que o fornecimento de ureia revestida resulta em falhas na sincronia entre a degradação dos carboidratos fibrosos e desta fonte de NNP para a síntese de proteína microbiana. Com isso, provavelmente ocorre redução da disponibilidade de proteína metabolizável no intestino delgado, necessária para atendimento das exigências proteicas, prejudicando o desempenho animal.

Considerando que o tratamento Ureia+Ureia revestida também continha a metade de sua composição representada pelo componente mais solúvel das três fontes (Ureia), pode ter prejudicado o ganho de peso. Quando o nitrogênio amoniacal está em excesso no rúmen e não é utilizado de forma eficiente pelos microrganismos ruminais para síntese de proteína microbiana, é absorvido pela parede ruminal e metabolizado no fígado. O seu excesso no fígado aumenta os custos energéticos associados metabolismo do nitrogênio, "Ciclo da Ureia", para enfim poder excretar ureia via urina (VERBIC, 2002). Com isso, o animal passa a direcionar a energia ingerida para eliminar ureia ao invés de incorporar no corpo para síntese de tecidos.

Considerando que fontes de NNP são extensivamente degradadas no rúmen, a taxa na qual a energia é disponibilizada seja o fator mais limitante para síntese microbiana (PINA et al., 2010), uma vez que os carboidratos fibrosos apresentam lenta taxa de degradação. Desta forma, o fornecimento de fontes nitrogenadas de liberação mais lenta, como a ureia extrusada, provavelmente proporcionou aumento no fluxo de proteína microbiana para o abomaso, devido a sua média velocidade de solubilização no ambiente ruminal, aumentando a disponibilidade de proteína metabolizável para o animal (ÍTAVO et al., 2007a).

Quando se avalia o ganho de peso mensal, é possível observar que o ganho de peso dos animais reduz até o final do período de avaliação, mesmo com a suplementação (Tabela 5). Isto está associado a redução da disponibilidade de matéria seca, do teor de PB e da DIVMS e aumento do teor de FDN do material. Lembrando que no inicio do período experimental, os piquetes estavam vedados e no decorrer dos dias, os animais consumiram a forrageira, deixando apenas o material residual, que decaiu em qualidade (aumentou FDN, diminuiu PB) e quantidade (SILVA et al., 2009; MATEUS et al., 2011; SCHIO et al., 2011).

Assim, ao final de 120 dias de ocupação, a disponibilidade de matéria verde apresentou-se muito aquém do necessário para manter o desempenho adequado de novilhos em fase de recria. A disponibilidade de 2.0t MS verde/ha de pastagem acarreta redução do consumo de pasto e aumento do tempo de pastejo, em função da menor oferta, afetando negativamente desempenho animal (NRC, 1996).

Quando o objetivo da suplementação é obter ganhos de até $0,5 \mathrm{~kg} /$ dia, é obrigatória a inclusão de fontes de energia e proteína no suplemento (SILVA et al., 2009). A suplementação durante todo o período seco é recomendada e o consumo pode variar entre $0,1 \%$ a $0,6 \%$ do peso corporal, de acordo com o objetivo a ser alcançado e a disponibilidade de massa de forragem para não limitar o consumo do animal (ÍTAVO et al., 2007b).

No trabalho é possível observar que mesmo com o adequado fornecimento de suplemento, no mês de outubro, a redução drástica da disponibilidade e valor nutritivo da pastagem promoveu redução do ganho de peso em todos os tratamentos (Tabela 5). No entanto, mesmo em situação adversa, a suplementação com ureia 
Rev. Bras. Saúde Prod. Anim., Salvador, v.17, n.3, p.448-460 jul./set., $2016 \quad \underline{\text { http://www.rbspa.ufba.br }}$ ISSN 15199940

extrusada evitou perdas de peso mais drásticas $(\mathrm{P}<0,05)$.

Quando avaliaram desempenho de novilhos suplementados em pastagens de Brachiaria brizantha com mistura mineral, mineral acrescida de ureia, enxofre e fubá, e mistura mineral acrescida de ureia extrusada durante o período seco, Ítavo et al. (2008) também observaram perdas de peso dos animais em todos os tratamentos $(-0,10 \mathrm{~kg} /$ dia - suplementação com mineral e $-0,06 \mathrm{~kg} /$ dia para suplementação com mistura mineral acrescida de fonte nitrogenada ureia ou ureia extrusada).

$\mathrm{O}$ tratamento com ureia extrusada proporcionou ganho de carcaça 4,9\% superior $(\mathrm{P}<0,05)$ ao tratamento Ureia+Ureia extrusada+Ureia revestida (1,63@/animal), 11,76\% superior ao tratamento Ureia+Ureia revestida (1,53 @/animal) e 20,4\% superior ao tratamento Ureia+Ureia extrusada (1,42@/animal)
(Tabela 5). Este resultado está associado ao maior ganho de peso e peso corporal final apresentado pelos animais deste tratamento (Tabela 5).

O tratamento Ureia extrusada apresentou receita ( $\$$ 208,29) superior $(\mathrm{P}<0,05$; Tabela 6) aos valores de receita tratamentos Ureia+Ureia extrusada+Ureia revestida (R\$ 199,41), Ureia+Ureia revestida (RS 186,56) e Ureia+Ureia extrusada (R\$173,19).

Esses resultados estão associados aos distintos desempenhos dos animais e valores de preço dos suplementos. $\mathrm{O}$ tratamento Ureia extrusada apresentou custo de R $\$ 1,01 / \mathrm{kg}$ de ganho, valor similar ao observado no tratamento Ureia+Ureia revestida ( $\mathrm{R} \$ 1,01 / \mathrm{kg}$ ganho). Esses valores são inferiores aos observados nos tratamentos Ureia+Ureia extrusada+Ureia revestida (R $\$ 1,20 / \mathrm{kg}$ ganho) e Ureia+Ureia extrusada ( $\mathrm{R} \$ 1,39 / \mathrm{kg}$ ganho).

Tabela 6. Avaliação econômica da produção de novilhos Nelore suplementados em pastagem diferida de Brachiariabrizantha $\mathrm{cv}$. MG-4

\begin{tabular}{|c|c|c|c|c|}
\hline \multirow[b]{2}{*}{ Variáveis } & \multicolumn{4}{|c|}{ Tratamentos $^{\#}$} \\
\hline & $\begin{array}{c}\text { Ureia+Ureia } \\
\text { extrusada+Ureia } \\
\text { revestida }\end{array}$ & $\begin{array}{l}\text { Ureia+Ureia } \\
\text { revestida }\end{array}$ & $\begin{array}{l}\text { Ureia+Ureia } \\
\text { extrusada }\end{array}$ & $\begin{array}{c}\text { Ureia } \\
\text { extrusada }\end{array}$ \\
\hline Receita (R\$/animal) & 199,41 & 173,19 & 186,56 & 208,29 \\
\hline $\begin{array}{l}\text { Custo de ganho (R\$/kg PV } \\
\text { ganho) }\end{array}$ & 1,20 & 1,39 & 1,01 & 1,01 \\
\hline $\begin{array}{l}\text { Custo diário com } \\
\text { suplemento }(\mathrm{R} \$ / \text { dia })\end{array}$ & 0,47 & 0,47 & 0,37 & 0,41 \\
\hline $\begin{array}{l}\text { Custo total com suplemento } \\
\text { (R\$/animal) }\end{array}$ & 56,58 & 56,73 & 44,42 & 49,67 \\
\hline $\begin{array}{l}\text { Margem Líquida } \\
\text { (R\$/animal) }\end{array}$ & 142,83 & 116,46 & 142,14 & 158,63 \\
\hline $\begin{array}{l}\text { Margem Líquida }(\mathrm{R} \$ / \mathrm{kg} \\
\mathrm{PV} \text { ganho) }\end{array}$ & 3,03 & 2,84 & 3,22 & 3,22 \\
\hline $\begin{array}{l}\text { Margem Líquida (R\$/@ } \\
\text { produzida) }\end{array}$ & 87,38 & 82,04 & 92,95 & 92,91 \\
\hline \multicolumn{5}{|c|}{ 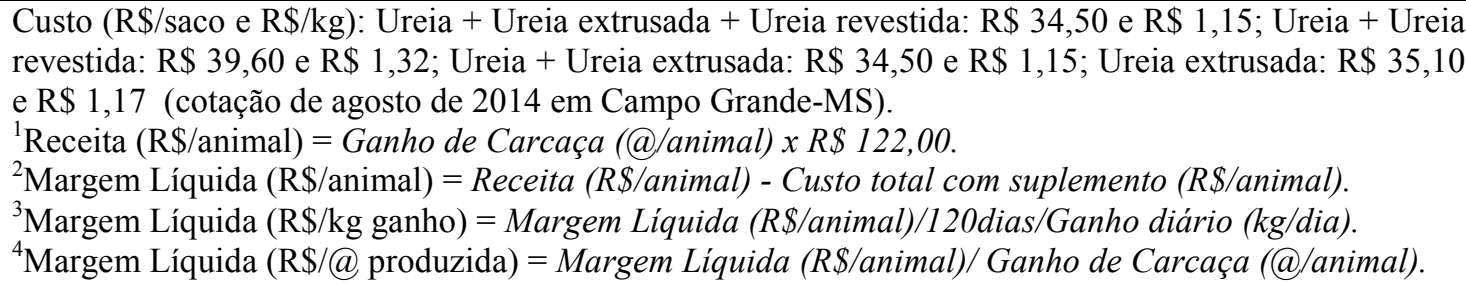 } \\
\hline
\end{tabular}


Da mesma forma, houve diferenças do custo diário entre os tratamentos, com médias de R\$ 0,37/dia para o tratamento Ureia+Ureia revestida, $\mathrm{R} \$ 0,41 /$ dia para Ureia extrusada e R\$ $0,47 /$ dia para os tratamentos Ureia+Ureia extrusada e Ureia+Ureia extrusada+Ureia revestida. Este resultado era esperado, uma vez que os custos das fontes nitrogenadas combinadas são distintos (Tabela 6).

Observa-se superioridade da margem líquida para o tratamento Ureia extrusada (R\$ 158,20/animal) sobre os demais tratamentos: Ureia+Ureia extrusada+Ureia revestida (R\$ 142,83), Ureia+Ureia revestida (R\$ 142,14) e Ureia+Ureia extrusada (R\$ 116,46). Esses valores correspondem a $9,7 \%, 10,1 \%$ e $35,8 \%$, respectivamente.

Tais resultados sugerem a melhor eficiência do uso da ureia extrusada como fonte de NNP em suplementos para recria de bovinos em pastagens diferidas. Entretanto, ao se avaliar a margem líquida por arroba e por ganho de peso, observa-se que o tratamento Ureia extrusada apresentou médias similares ao tratamento Ureia+Ureia revestida (R\$ 92,91/@ e R $\$ 3,22 / \mathrm{kg}$ ganho vs R\$ 92,95/@ e R $\$ 3,22 / \mathrm{kg}$ ganho, respectivamente).

O fornecimento de suplementos com fontes de NNP com características de solubilidade média (ureia extrusada) no ambiente ruminal traz benefícios para o sistema de produção desde que os custos relacionados a compra das fontes sejam reduzidos. No trabalho, a ureia extrusada pode ser a mais indicada como fonte nitrogênio não proteico para recria de novilhos em pastagens diferidas, pois o melhor desempenho foi associado ao menor custo, já que os animais apresentaram ganho de peso superior mesmo com menor consumo de suplemento.

Um dos fatores preponderantes com relação à produção de animais em sistema de suplementação a pasto consiste na definição da suplementação e os objetivos a ser alcançados. Devem ser estabelecidas estratégias de suplementação que viabilizem os padrões de crescimento e utilização eficiente do pasto pelo animal (MATEUS et al., 2011). Os custos de aquisição, a qualidade das fontes nitrogenadas do suplemento e o desempenho animal são fatores determinantes para o sucesso financeiro da suplementação de novilhos na fase de recria.

Recomenda-se a utilização de ureia extrusada como fonte de nitrogênio não protéico (NNP) em suplementos para recria de novilhos Nelore em pastagem diferida. Porém, o sucesso para redução dos custos de produção no campo depende das variações entre as cotações das fontes de NNP nas diferentes regiões do país.

\section{REFERÊNCIAS}

CÓSER, A.C.; MARTINS, C.E.; DERESZ, F. Metodologias para estimativa da produção de forragem em pastagem de capim-elefante. Juiz de Fora, MG: Embrapa Gado de Leite, 2002. $16 \mathrm{p}$.

COSTA, V.A.C.; DETMANN, E.; PAULINO, M.F.; VALADARES FILHO, S.C.; HENRIQUES, L.T.; CARVALHO, I.P.C.; VALENTE, T.N.P. Consumo e dinâmica ruminal da fibra em detergente neutro em bovinos em pastejo no período das águas recebendo suplementação com nitrogênio nãoproteico e/ou proteína verdadeira.

Revista Brasileira de Zootecnia, v.40, n.12, p.2805-2814, 2011. 
Rev. Bras. Saúde Prod. Anim., Salvador, v.17, n.3, p.448-460 jul./set., $2016 \quad \underline{\text { http://www.rbspa.ufba.br }}$ ISSN 15199940

DETMANN, E.; SOUZA, M.A.; VALADARES FILHO, S.C.; QUEIROZ, A.C.; BERCHIELLI, T.T.; SALIBA, E.O.L.; CABRAL, L.S.; PINA, D.S.; LADEIRA, M.M.; AZEVEDO, J.A.G. Métodos para Análise de Alimentos INCT - Ciência Animal. 1. ed. Visconde do Rio Branco: Suprema, 2012. 214p.

ÍTAVO, L.C.V.; ÍTAVO, C.C.B.F.; DIAS, A.M.; NOVAIS, M.F.S.M.; SILVA, F.F.; MATEUS, R.G; SCHIO, A.R. Desempenho produtivo e avaliação econômica de novilhos suplementados no período seco em pastagens diferidas, sob duas taxas de lotação. Revista Brasileira de Saúde e Produção Animal [online], v.8, n.3, p.229-238, 2007a.

ÍTAVO, L.C.V.; ÍTAVO, C.C.B.F.; DIAS, A.M.; GOMES, R.C.; ANDERSON, H.C.; SILVA, F.F. Terminação de diferentes categorias de bovinos suplementados em pastagens diferidas. Revista Brasileira de Saúde e Produção Animal [online], v.8, n.4, p.309-316, $2007 b$.

ÍTAVO, L.C.V.; TOLENTINO, T.C.P.; ÍTAVO, C.C.B.F.;GOMES, R.C.; DIAS, A.M.; SILVA, F.F.Consumo, desempenho e parâmetros econômicos de novilhos Nelore e F1 Brangus-Nelore terminados em pastagens, suplementados com mistura mineral e sal nitrogenado com ureia e amireia. Arquivo Brasileiro Medicina Veterinária e Zootecnia, v.60, p.419-427, 2008.

LIZARAZO, A.C.; MENDOZA, G.D.; KÚ J.; MELGOZA, L.M.; CROSBY, M. Effects of slow-release urea and molasses on ruminal metabolism of lambs fed with low-quality tropical forage. Small

Ruminant Research, v.116, p.28-31, 2014.
MATEUS, R.G.; SILVA, F.F.; ÍTAVO, L.C.V.; PIRES, A.J.V.; SILVA, R.R.;

SCHIO, A.R. Suplementos para recria de bovinos Nelore na época seca: desempenho, consumo e digestibilidade dos nutrientes. Acta Scientiarum. Animal Sciences, v.33, n.1, p.87-94, 2011.

NATIONAL RESEARCH COUNCIL NRC. Nutrients requeriments of beef cattle. 7.ed. Washington, D.C., 2000. $244 p$.

NATIONAL RESEARCH COUNCIL NRC. Nutrient requirements of beef cattle. 7.ed. Washington, D.C.: National Academy Press, 1996. 242p

PINA, D.S.; VALADARES, R.D.F.; VALADARES FILHO, S.C.;

CHIZZOTTI, M.L. Degradação ruminal da proteína dos alimentos e síntese de proteína microbiana. In: VALADARES FILHO, S. de C.; MARCONDES, M.I.; CHIZZOTTI, M.L.; RODR, P.V.

Exigências Nutricionais de Zebuínos Puros e Cruzados - BR-CORTE. 2.ed. Viçosa, MG: Universidade Federal de Viçosa, 2010. p.13-46.

RIBEIRO, S.S.; VASCONCELOS, J.T.; MORAIS, M.G.; ÍTAVO, C.C.F.B.; FRANCO, G.L. Effects of ruminal infusion of a slow-release polymercoated urea or conventional urea on apparent nutrient digestibility, in situ degradability, and rumen parameters in cattle fed low-quality hay. Animal Feed Science and Technology, v.164, p.5361, 2011.

SCHIO, A.R.; VELOSO, C.M.; SILVA, F.F.; ÍTAVO, L.C.V.; MATEUS, R.G.; SILVA, R.R. Ofertas de forragem para novilhas nelore suplementadas no período de seca e transição seca/águas. Acta Scientiarum.Animal Sciences, v.33, n.1, p.9-17, 2011. 
Rev. Bras. Saúde Prod. Anim., Salvador, v.17, n.3, p.448-460 jul./set., $2016 \quad \underline{\text { http://www.rbspa.ufba.br }}$ ISSN 15199940

SILVA, F.F.; SÁ, J.F.; SCHIO, A.R.;

ÍTAVO, L.C.V.; SILVA, R.R.;

MATEUS, R.G.Suplementação a pasto: disponibilidade e qualidade $\mathrm{x}$ níveis de suplementação x desempenho. Revista Brasileira de Zootecnia, v.38, p.371389, 2009 (Supl. especial).

VERBIC, J. Factors affecting microbial protein synthesis in the rumen with emphasis on diets containing forages.

Viehwirtschaftliche Fachtagung, v.24 25, p.1-6, 2002.

Data de recebimento: 06/07/2015

Data de aproximação: 29/07/2016 